


\title{
¿Qué hacer con el ángel? J. L. Borges y F. L. Bernárdez, dos formas de escribir la experiencia mística
}

\author{
Lucas Adur
}

Este trabajo propone una lectura de dos textos de escritores argentinos, publicados casi contemporáneamente, El buque (1935) de Francisco Luis Bernárdez y "El acercamiento a Almotásim" (1936) de Jorge Luis Borges, que pueden considerarse como dos modos, diametralmente opuestos, de dar cuenta de una experiencia mística. Una "positiva", que apuesta por un discurso conceptual y una "negativa" que opta por la alusión, la paradoja y el silencio. El poema de Bernárdez tiene en su centro una revelación mística, experimentada por el yo lírico, que es transmisible en términos discursivos y que implica una propuesta moral. En este sentido, puede pensarse que El buque es representativo de la estética sostenida por un grupo de poetas católicos que, apoyados en la teología escolástica, proponían que la literatura debía estar al servicio de la difusión del mensaje cristiano y del renacimiento espiritual del pueblo. Borges escribe una reseña de este poema y, meses después, "El acercamiento a Almotásim", relato que puede leerse como una respuesta polémica a la forma de presentar la experiencia mística que propone el texto de Bernárdez. Frente al "decir excesivo" que atribuye al poeta católico, Borges subraya en su escritura la dimensión inefable, intransmisible que caracteriza para él a toda experiencia directa de lo trascendente.

PALABRAS ClaVE: Borges, Bernárdez, posicionamiento, mística, inefable.

This paper proposes a reading of two texts of Argentine writers, published almost simultaneously, El buque (1935) by Francisco Luis Bernardez and "El acercamiento a Almotásim" (1936) by Jorge Luis Borges, which may be con- 
sidered two ways, diametrically opposed, to talk about a mystical experience. "Positively", focusing on conceptual discourse and a "negatively" choosing allusion, paradox and silence.

Bernardez's poem includes a mystical revelation experienced by the lyrical subject, which is transmitted in conceptual terms and involves a morale. In this sense, El buque represents the position of a group of Catholic poets proposed that literature should aim at service of the diffusion of Christian message and the spiritual renaissance of the Argentinian people. Borges made a review of this poem and, a few months later, wrote "El acercamiento a Almotásim". We understand that this story can be read as a polemical response to El buque and as a different way to give an account of a mystical experience.

KEYWORDS: Borges, Bernárdez, positioning, mysticism, ineffable.

Fecha de recepción: 8 de julio de 2013

Fecha de aceptación: 23 de septiembre de 2013 
Lucas Adur

Universidad de Buenos Aires

Facultad de Filosofía y Letras

\section{¿Qué hacer con el ángel? J. L. Borges y F. L. Bernárdez, dos formas de escribir la experiencia mística}

\section{Borges y la mística}

La relación de la obra de Jorge Luis Borges con la mística es una cuestión que permanece abierta en la profusa bibliografía crítica dedicada al escritor. Existe cierto consenso en considerar que textos como "El Aleph", "La escritura del Dios", "Mateo, Xxv, 30" o "El Congreso" pueden leerse en diálogo con esa tradición, en tanto plantean un problema central para la literatura mística: el de la paradójica expresión de lo inefable. ${ }^{1}$ Las opiniones, en cambio, están divididas con respecto a si Borges puede considerarse o no, un místico, en el sentido de haber atravesado él mismo por una experiencia íntima y directa de lo trascendente, ${ }^{2}$ que

\footnotetext{
${ }^{1}$ William James sostiene que la primera de las características que definen la experiencia mística es la "inefabilidad": "El sujeto del mismo afirma inmediatamente que desafía la expresión, que no puede darse en palabras ninguna explicación adecuada que explique su contenido" (Variedades de la experiencia religiosa, 420). Siguiendo a este autor, Luce López-Baralt habla de la "cualidad inefable del hecho místico: es literalmente indescriptible e intransferible a quien no lo haya experimentado a su vez" ("La experiencia mística", 13). En el mismo sentido, Gershom Scholem señala la naturaleza paradójica de la escritura mística: “¿cómo pueden expresar las palabras una experiencia para la cual no existe un símil adecuado en el mundo finito del hombre?” (Grandes tendencias, 24).

${ }^{2}$ Scholem, luego de revisar algunas definiciones de otros autores, propone entender la experiencia mística como "la experiencia fundamental del yo más íntimo que entra en contacto inmediato con Dios o con la realidad metafísica" (Grandes tendencias, 24).
} 
funcionaría como sustrato de textos como los mencionados. Así, por ejemplo, María Kodama (“Jorge Luis Borges y la experiencia mística”), Luce López-Baralt (“¿Vivió Jorge Luis Borges...”, 252; “Los paseos de Borges por Constitución”) y Palazuelos Montesinos ("Jesús en la literatura de Borges", 233-237) afirman, citando testimonios del propio escritor, que Borges vivió experiencias místicas que plasmó en su literatura, mientras que Carlos Gamerro ("Borges y la tradición mística", 95-96, 110) y Robin Lefere (Borges..., 117-118) niegan de plano esa posibilidad. ${ }^{3}$ Sin pretender zanjar la cuestión, digamos que desde nuestra perspectiva resulta más pertinente y productivo que indagar la biografía de Borges, estudiar su producción para determinar de qué modo el escritor concibe la relación entre mística y literatura y cómo afronta el problema - literario- de expresar lo inexpresable.

En este sentido, el presente trabajo propone leer uno de los primeros relatos de Borges vinculados con la tradición mística, "El acercamiento a Almotásim" (Historia de la eternidad, 1936), como parte de una toma de posición del escritor en el contexto del campo literario argentino de aquel momento. ${ }^{4}$ Esto implica poner el texto en serie con otros del mismo

${ }^{3}$ La exponente más significativa de la tesis de que Borges vivió experiencias místicas es, indudablemente, Luce López-Baralt, quien se basa en una entrevista realizada por W. Barnstone y en otras efectuadas por ella misma ( $c f r$. López Baralt y Baez, “¿Vivió Jorge Luis Borges...?”, 252). Sostiene la existencia de dos experiencias de este tipo, una de las cuales habría quedado plasmada en "Sentirse en muerte" (El idioma de los argentinos, 1928) y la otra en "Mateo, xxv, 30" (La Nación, 1953). Robin Lefere, por su parte, refuta esta suposición, combinando argumentos textuales con otros de índole biográfica y psicológica: "Si bien para Luce López-Baralt no cabe duda de que estamos [en Mateo xxv, 30] 'ante una experiencia mística transformadora que efectivamente hubiera tenido lugar en Constitución, y si alega diversas confidencias orales para reforzar su tesis de un Borges místico, conviene subrayar la ambigüedad de este poema, no sólo por tratarse del personaje poético del paseante borgeano, sino precisamente por presentarlo en una situación sobrenatural, en términos hiperbólicos.[E] Disimular la verdad en un asunto tan trascendente [E] conllevaría una (ir)responsabilidad ética y filosófica que no se corresponde con el talante del hombre" (Lefere, Borges..., 116-118).

${ }^{4}$ Tomamos las nociones de "toma de posición" y "campo literario" de la teoría de Pierre Bourdieu: "El campo es una red de relaciones objetivas (de dominación o subordinación, de complementariedad o antagonismo, etc.) entre posiciones: por ejemplo, la que corresponde a un género como la novela o a un subgénero como la novela mundana, o, desde otro punto de vista, la que identifica a una revista, un salón o un cenáculo como los lugares de reunión de un grupo de productores. [...] A las diferentes 
autor y situarlo en relación con la producción de otros escritores que representan posicionamientos diversos al que Borges está construyendo en la década del treinta. ${ }^{5}$ En particular, en este artículo nos interesa detenernos en El buque (1935), obra del poeta católico Francisco Luis Bernárdez que Borges había reseñado unos meses antes de publicar su propio relato. Intentaremos mostrar que "El acercamiento a Almotásim" puede interpretarse como puesta en práctica de una concepción de la literatura mística que se opone radicalmente a la que sustenta la obra de Bernárdez. Si esta propone un acercamiento por la vía positiva, apelando a un discurso conceptual, modelado por la teología escolástica, el texto de Borges está marcado por la teología negativa o apofática que sostiene la incomprensibilidad de lo divino y la inefabilidad de toda experiencia trascendente. ${ }^{6}$

\section{La vía positiva: Francisco Luis Bernárdez De la vanguardia al catolicismo}

El buque, de Francisco Luis Bernárdez (1900-1978), fue editado por Sur en 1935. Su autor se había dado a conocer como parte de la generación de jóvenes vanguardistas que sacudieron el panorama literario argentino de los años veinte. Bernárdez participó en algunas de las principales revistas de aquel momento como Martín Fierro (1924-1927) y Proa (1924-1926), de la que llegó a ser uno de los directores; su poe-

posiciones [...] corresponden tomas de posición homólogas, obras literarias o artísticas evidentemente, pero también actos y discursos políticos, manifiestos, polémicas, etc." (Las reglas del arte, 342-343).

${ }^{5}$ Se ha señalado frecuentemente que la década del treinta marca un giro en el proyecto estético de Jorge Luis Borges, que implica diversos desplazamientos: un relativo "abandono" de la poesía, su incorporación al "grupo Sur", sus primeras incursiones en la ficción narrativa, entre otras ( $c f r$. Cobas Carral, "Modos de refundarse", 84-89). En nuestro "Hombres ya fulminados por Juvenal" hemos propuesto que, como parte de ese reposicionamiento debe considerarse su radical ruptura con el grupo de intelectuales católicos argentinos con los que había colaborado a fines de los años veinte.

${ }^{6}$ Para una breve introducción al contraste entre la "vía positiva" y la "vía negativa" en teología puede consultarse un ensayo del propio Borges, "De Alguien a Nadie" (recogido en Otras inquisiciones, 1952). 
mario Alcándara (1925), editado por Proa, era considerado entre los más representativos de la "nueva poesía argentina" (cfr. Evar Méndez, "Rol de Martín Fierro") y sus versos eran recogidos en la mayoría de las antologías de la vanguardia (ver por ejemplo, Vignale y Tiempo, Exposición de la actual poesía argentina). De estos primeros años de actividad literaria data su amistad con Jorge Luis Borges ( $c f r$. Rodríguez Monegal, Borges, 169-ss.). ${ }^{7}$ Hacia fines de la década del veinte, cuando el ciclo de la vanguardia estaba cerrándose (Montaldo, "Consagraciones”, 40), Bernárdez, junto a otros exmartinfierristas como Leopoldo Marechal y Ernesto Palacio se acerca al grupo de intelectuales católicos nucleados en torno a los Cursos de Cultura Católica (CCC) ${ }^{8}$ El escritor se integra al cenáculo Convivio, un desprendimiento de los CCC que

${ }^{7}$ Bernárdez y Borges debieron conocerse hacia 1924, cuando el primero aún residía en España, dado que ese año, siguiendo a Carlos García (El joven Borges, 25), intercambian ejemplares dedicados de sus libros. La iniciativa parece haber sido de Bérnardez, que le remitió Kindergarten (Madrid, 1923), al que Borges aludirá brevemente en una nota publicada en el primer número de Proa (1924). Por su parte, él le envío Fervor de Buenos Aires con la siguiente dedicatoria: “A Paco Luis Bernárdez, estas monedas de cobre a cambio de las suyas de oro" (apud García, El joven Borges, 25). Desde el regreso de Bernárdez a la Argentina, a fines de 1924, la amistad parece haberse consolidado. En 1926 Borges le dedica el poema "Elegía de Palermo" (Nosotros, núm. 210). Pese a que, a partir de 1930, el reposicionamiento de Borges lo sitúa en un lugar muy distante al de Bernárdez en el campo literario, la amistad entre ambos prosiguió. En uno de sus últimos libros publicados, La cifra (1981), Borges dedica el poema "Epílogo" a Bernárdez, que había fallecido pocos años antes.

${ }^{8}$ En otros trabajos nos hemos ocupado más detenidamente de estos artistas e intelectuales católicos y de su relación con Borges ( $c f r$. "Simpatías y diferencias", "Hombres ya fulminados por Juvenal", "El arte al servicio del renacimiento espiritual"). Recordemos aquí brevemente que, a partir de los años veinte comenzó a gestarse en Argentina un movimiento que alcanzó su plena madurez en la década siguiente y que los historiadores denominan "renacimiento católico" (Di Stéfano y Zanatta, Historia de la Iglesia, 403, Daniel Lvovich, Nacionalismo y antisemitismo, 207). Los animadores de este renacimiento fueron un grupo de jóvenes intelectuales, que buscaban elevar el prestigio y la influencia del catolicismo en el campo cultural argentino, con el fin de poder intervenir en las luchas políticas de esos años. Los Cursos de Cultura Católica (CCC), constituyeron un primer espacio de formación e intercambio, un ámbito de sociabilidad y un núcleo del que se desprendieron diversos emprendimientos. La literatura tuvo un lugar importante en su proyecto; el cenáculo Convivio y revistas como Criterio, Número y Sol y Luna, vinculadas estrechamente a los ccc, funcionaron como lugares de pertenencia y medios de difusión para poetas católicos, como Leopoldo Marechal, Ricardo Molinari o Francisco Luis Bernárdez, por mencionar a los más significativos. 
funcionaba como ámbito de reunión para poetas y artistas católicos y, ya en la década del treinta, colabora con medios confesionales como Criterio, Número o Sol y Luna.

Promediando esa década, cuando publica El buque, Bernárdez está claramente posicionado como un intelectual católico. De hecho, el libro en cuestión está dedicado "A los Cursos de Cultura Católica"9 y se cierra con un "Deo Gratias" (Bernárdez, El buque, 75, 115). La obra puede entonces considerarse representativa de un posicionamiento en el campo literario argentino, el de los "poetas católicos" o "poetas del Convivio", en el que podríamos situar también a escritores como Leopoldo Marechal, Ricardo Molinari, Ignacio Anzoátegui y Osvaldo H. Dondo (cfr. Martínez Cuitiño, La vanguardia católica). Aunque sus producciones presentan, en muchos casos, notables diferencias en términos formales, el hecho de compartir proyectos editoriales, medios de difusión y espacios institucionales; su adscripción a la filosofía y teología escolásticas - que era la base doctrinaria de $\operatorname{los} \mathrm{CCC}-{ }^{10} \mathrm{y}$, especialmente, su autoidentificación como católicos les permitían presentarse como un colectivo relativamente homogéneo dentro el campo literario. ${ }^{11}$

\section{Juan de la Cruz y 'El buque': la noche oscura y el poema claro}

Considerado por muchos críticos como la obra maestra de Bernárdez (Maturo, "Francisco Luis Bernárdez", 15), El buque consta de 160 liras, la misma combinación métrica utilizada, por ejemplo, por san Juan de

${ }^{9}$ Gérard Genette ha señalado que las dedicatorias exhiben públicamente "una relación intelectual, real o simbólica" (Umbrales, 116) entre dedicador y dedicatario. Entendemos que, en este caso, la dedicatoria a una institución puede leerse como índice de pertenencia.

${ }^{10} \mathrm{En}$ "El arte al servicio del renacimiento espiritual" hemos mostrado que en Arte y escolástica, obra del filósofo francés Jacques Maritain, este grupo encontró las bases para definir su estética en el marco de la filosofía tomista.

${ }^{11}$ En el prólogo a la Antología poética argentina (1941), que compiló junto a Adolfo Bioy Casares y Silvina Ocampo, Borges se refiere a este grupo con el irónico mote de "poetas neotomistas" - aludiendo evidentemente a la teología que se enseñaba en los CCC - y subraya las diferencias formales entre las poéticas de Bernárdez, Marechal y Molinari (Borges, Antología, 10). 
la Cruz en su "Noche oscura" y su "Cántico espiritual”. La afinidad no es únicamente formal: el argumento del poema puede sintetizarse como la narración de una experiencia mística. El texto comienza con el yo lírico disponiéndose a escribir, de noche, en una casa silenciosa que sin duda remite a la "noche oscura" y la "casa sosegada" del poeta de Ávila (Juan de la Cruz, "Noche oscura", 3). En ese contexto el poeta escucha una música misteriosa (Bernárdez, El buque, 80-83), que lo lleva a acercarse a la ventana "para ver al causante del concierto" (83). No logra encontrarlo y, en su busca, sale al jardín; ${ }^{12}$ allí divisa una forma al principio difusa, que identificará como un buque que "vuela por el cielo" (94). Cuando este finalmente desciende, el poeta ingresa y lo recorre, buscando siempre el origen de ese canto, sin encontrar a nadie. Sin embargo, en ese deambular por el barco desierto, el poeta alcanza una revelación mística. Esta adquiere una forma muy singular: el yo lírico escucha una voz, que le "pide" y le "dice" una serie de cosas, que se detallan en estilo indirecto:

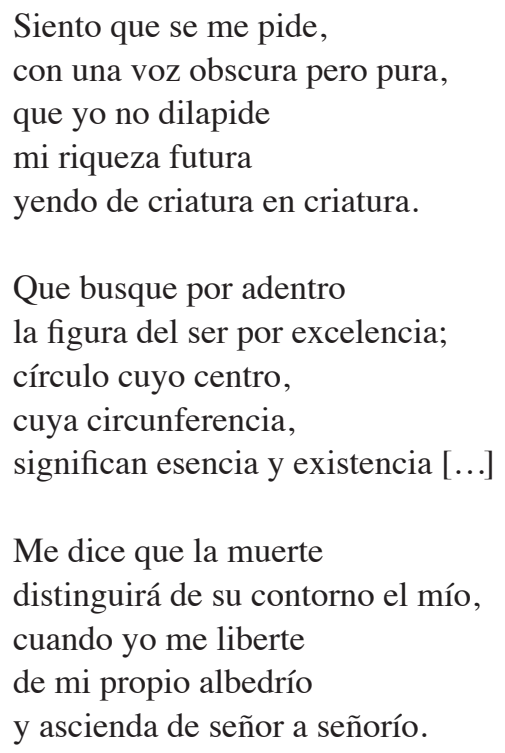

\footnotetext{
${ }^{12}$ Podemos ver en el jardín una nueva referencia a Juan de la Cruz, al "huerto deseado" donde se produce el encuentro (místico) entre la esposa y su Amado ("Cántico espiritual”, 14, ver también los “Comentarios en prosa al Cántico espiritual”, 257).
} 
Que todavía es hora

de remediar esta ceguera mía,

buscando sin demora

la verdadera vía

que ha de llevarme al verdadero día.

Que no tendré remedio

mientras el apetito vagabundo

no sepa ver el medio

de vivir en el mundo

con alma viva y cuerpo moribundo.

Que para que lo sepa

lo mejor es matar esta codicia,

de modo que no quepa

yo sino la justicia

dentro del ser exento de malicia

(Bernárdez, El buque, 105-107).

Mercedes Roffé anota a propósito de estos versos: “Allí donde para los místicos la transubstancialización era gozo, muerte, disolución de los sentidos, Bernárdez pretende una 'encarnación' discursiva" (El buque, 105). En efecto, como hemos dicho, la experiencia mística es generalmente definida como inefable, y quienes buscan dar cuenta de ella acuden a metáforas, símbolos paradójicos o "dislates", como los denomina Luce López-Baralt, "para decir algo de esa oscuridad que es exceso de luz y que implica el conocimiento trascendente que no se obtiene por la razón discursiva" ("La experiencia mística", 9). También resulta extraño el tono de reproche que tiene la revelación en El buque, en tanto, "para los místicos [...] la revelación no podía conllevar condena alguna en tanto era, ella misma, la Gracia" (Roffé, El buque, 107).

Podemos afirmar, entonces, que la obra de Bernárdez constituye una apropiación muy sui generis de la tradición mística y, especialmente, de la representada por Juan de la Cruz. Si bien se perciben algunas afinidades formales y temáticas, el autor no recurre a las paradojas o al imaginario erótico-unitivo del reformador carmelita, sino que apela a un discurso conceptual, fuertemente modelado por la teología escolástica. Frente a la oscuridad y ambigüedades que caracterizan buena parte de 
la poesía mística, El buque transmite de un modo mucho más directo su mensaje moralizante. ${ }^{13}$ De esta forma, Bernárdez contribuye a realizar el proyecto que había dado origen al Convivio: lograr que la vocación de los artistas fuera puesta al servicio del "renacimiento espiritual" del pueblo. ${ }^{14}$ Como veremos enseguida, este uso didáctico de la mística, será objetado por Borges, quien señalará, como crítico, lo que considera errores estéticos del texto de Bernárdez, y propondrá, como narrador, un acercamiento distinto a esa misma tradición.

\section{Bernárdez leído por Borges}

Algunos meses después de la aparición de El buque, Borges publica una reseña en el número 2 de la revista Obra (enero 1936). Como en otras recensiones de Borges, el juicio sobre la obra ostenta una considerable ambigüedad. ${ }^{15}$ En principio parece elogioso: "El buque justifica con esplendor la fama de Bernárdez" (Borges, "El buque”, 133), "la destreza métrica y sintáctica de Bernárdez es continuamente admirable" (133), "En conjunto: un libro admirable" (135). Sin embargo, la reticencia de Borges es inmediatamente perceptible. Las reservas que declara frente a este texto "admirable" pueden darnos una idea de la distancia entre su propia concepción de la literatura mística y la que subyace en la obra de Bernárdez y la de algunos de los poetas católicos del Convivio.

${ }^{13}$ En su estudio sobre La poesía religiosa argentina, Aragón señala este rasgo como característico de la obra de Bernárdez: "Su expresión es directa, sencilla y simple [...] Busca con ella una comunicación fácil, como didáctica, sin énfasis que turben la enunciación clara, reposada del asunto" (46).

${ }^{14}$ En el discurso inaugural de las actividades del Convivio en 1929, Atilio Dell'Oro Maini, su fundador y primer director, había formulado del siguiente modo los objetivos del cenáculo: "Convivio tiene por fin reunir a jóvenes, escritores y artistas, en una amistosa y activa solidaridad para darles ocasión y estímulos — dentro de un conocimiento serio y penetrante de la doctrina católica - de vigorizar y exaltar su personal vocación en beneficio del renacimiento espiritual de nuestro pueblo (Dell'Oro Maini, "Las características del Convivio", 173-174).

${ }^{15}$ Véase, por ejemplo, su reseña de The Four of Hearts de Ellery Queen (El hogar, mayo 1939) o la de The Killer and the Slaine, de Hugh Walpole ("La última invención de Hugh Walpole", La Nación, enero 1943) y la nota necrológica consagrada a Leopoldo Lugones en Sur núm. 41 (1938). 
El principal problema que Borges detecta en el poema es su didactismo: "El defecto del 'Buque' - ¿y qué poema de ochocientos versos no adolece de alguno? - es la naturaleza didáctica, para no decir escolar, de la revelación que le es deparada al autor. Hay estrofas que son nociones elementales de teología, versificadas" (135). Ligado a esto, Borges también objeta la selección léxica de Bernárdez: ${ }^{16}$ "Su vocabulario no es menos justo - si bien abusa alguna vez del dialecto escolástico, no siempre aligerado por palabras de un ambiente distinto" ("Francisco Luis Bernárdez", 133). ${ }^{17}$ En efecto, el poema abunda en términos como "forma y figura" (Bernárdez, El buque, 98) "esencia y existencia" (105) o "causa primera" (110) y varios fragmentos pueden considerase "teología (escolástica) versificada":

\author{
Si por la arquitectura \\ se conoce el valor del arquitecto, \\ por la que así fulgura \\ no siendo sino efecto \\ se conoce la causa sin defecto (99). \\ Su música y su letra \\ son la misericordia y la justicia: \\ con una nos penetra, \\ con otra nos enjuicia \\ al mismo tiempo que nos acaricia (105).
}

El punto central de la crítica borgeana está relacionado con el modo en que Bernárdez pretende dar cuenta de una experiencia mística o, en un sentido más amplio, con la forma en que articula el discurso literario

${ }^{16}$ Siguiendo a Charaudeau y Maingueneau, la selección léxica puede considerarse entre los elementos que permiten definir un posicionamiento en el campo (Diccionario, 452). En este sentido, el señalamiento crítico de Borges sobre el "dialecto escolástico" del poema apunta a la vinculación de Bernárdez con el grupo de intelectuales católicos neotomistas de los CCC.

${ }^{17}$ Anotemos, de paso, que la percepción de que el razonamiento teológico impide, al menos por momentos, la fluidez del poema, no es exclusiva de Borges. Giusti en una nota publicada en Nosotros en 1936 sostiene: "a medida que el pensamiento neoescolástico avanza el razonamiento traba a veces la marca de la lira, convirtiendo en discursiva la estrofa lírica" (apud Roffé, El buque, 25). 
con el discurso teológico. Como ha señalado Raúl Roque Aragón, Bernárdez es quizá el caso más notorio de cierta subordinación de la poesía a la teología escolástica, que se constata en algunas producciones de los poetas del Convivio:

El conocimiento teológico abrió la perspectiva sobre esa realidad que la poesía religiosa comenta. Tanto fascinó su descubrimiento que la poesía empieza abriéndose a la teología en lugar de coincidir con ella - a su modo- en el objeto que les es común. Hay estrofas de Bernárdez, por ejemplo, que son la versificación de argumentos escolásticos (La poesía religiosa argentina, 42$).{ }^{18}$

Borges caracteriza la revelación que es el punto culminante del poema como "didáctica" y "escolar". Antes hemos citado el fragmento en que el yo lírico "escucha" y transcribe a lo largo de siete liras una serie precisa de "instrucciones" para su vida. Desde la perspectiva borgeana, eso es decir demasiado. Bernárdez, hemos propuesto, descarta las oscuridades y ambigüedades de cierta poesía mística en beneficio de un "mensaje" moralizante (o cristianizante) que pueda ser fácilmente comprendido por sus lectores. Para Borges, este afán de univocidad, de fijación de sentidos conspira contra la calidad estética. Podemos pensar que, para el escritor, ésta no es una característica exclusiva de Bernárdez sino, más ampliamente, del posicionamiento que representa en el campo, vinculado al renacimiento católico argentino. De hecho, en un texto de 1933, "Elementos de preceptiva", encontramos una apreciación similar sobre otra forma - muy distinta - del discurso católico. Borges proponía en ese ensayo el estudio de los hallazgos retóricos de una serie de textos muy heterogéneos (el comienzo de una milonga, dos versos de un tango, uno de Paradise Lost, una estrofa de un poema de Cummings). El último ejemplo que analiza es, por el contrario, "de equivocación” y se trata de "un cartel callejero de exhortación católica":19

${ }^{18}$ Nótese que, sin citarlo, Aragón coincide casi literalmente con el señalamiento de Borges a propósito de El buque.

${ }^{19}$ Para Borges, las manifestaciones públicas y militantes de la fe, que caracterizaban al renacimiento católico, eran objetables per se. En "Modos de G.K. Chesterton", lamenta "el catolicismo petulante y autoritario que padece nuestra república" (18) y 
Los jóvenes, sin experiencia creen en los hombres.

Los adultos, que han vivido, que han meditado, creen en Dios.

Sospecho que la obligación de ser inequívoco ha desfigurado un buen borrador, que paso a restaurar.

Los jóvenes, sin experiencia, creen en los hombres.

Los hombres creen en Dios.

Basta el contrapeso de jóvenes para que hombres equivalga con plenitud a las siete palabras eliminadas (Borges, "Elementos de preceptiva", 124).

La búsqueda de explicitar didácticamente el sentido ("la obligación de ser inequívoco") lleva al error estético. El discurso católico - tanto en un cartel callejero, como en un poema místico- peca por exceso. Como veremos, en la producción de Borges, mejor que decir es sugerir, aludir o callar.

\section{La vía negativa: Jorge Luis Borges}

Experiencias místicas en la literatura borgeana:

de lo decible a lo inefable

De la reseña que Borges realiza de El buque es posible, entonces, extraer algunos elementos para delinear su propia concepción de la poesía mística. Se trata de elementos fundamentalmente negativos: el escritor señala lo que no debe hacerse, lo que rechaza y, en este sentido, toma distancia del autor de El buque y del posicionamiento del que este participa. Para completar el panorama, conviene indagar los textos donde Borges ensaya su propia versión de la escritura de un éxtasis místico.

Como ha señalado Carlos Gamerro, de la lectura de estos textos es necesario concluir que, en línea con los grandes escritores místicos, Borges concibe la experiencia de lo trascendente como inefable: "Tener la visión es difícil, pero posible. Lo imposible es comunicarla" ("Borges y la tradición mística”, 100). Así se constata en los relatos y el poema que hemos mencionado al comienzo de este artículo. "El Aleph"

lo contrapone con la "urbanidad" de la religiosidad inglesa. Hemos desarrollado este punto en "Hombres ya fulminados por Juvenal". 
(Sur 131, 1945), "La escritura del Dios" (Sur 172, 1949), "Mateo, Xxv, 30" (La Nación, 1953) o "El Congreso" (1971) muestran, justamente, ese límite, la imposibilidad del lenguaje de dar cuenta acabadamente de una experiencia mística:

Arribo, ahora, al inefable centro de mi relato; empieza, aquí, mi desesperación de escritor [...] ¿cómo transmitir a los otros el infinito Aleph, que mi temerosa memoria apenas abarca? Los místicos, en análogo trance, prodigan los emblemas [...] (“El Aleph”, 624).

Entonces ocurrió lo que no puedo olvidar ni comunicar. Ocurrió la unión con la divinidad, con el universo (no sé si estas palabras difieren) ("La escritura del Dios", 598).

Desde el invisible horizonte

y desde el centro de mi ser, una voz infinita

dijo estas cosas (estas cosas, no estas palabras, que son mi pobre traducción temporal de una sola palabra)

("Mateo xxv, 30", 252).

Las palabras son símbolos que postulan una memoria compartida. La que ahora quiero historiar es mía solamente; quienes la compartieron han muerto. Los místicos invocan una rosa, un beso, un pájaro que es todos los pájaros, un sol que es todas las estrellas y el sol, un cántaro de vino, un jardín o el acto sexual. De estas metáforas ninguna me sirve para esa larga noche de júbilo, que nos dejó, cansados y felices, en los linderos de la aurora ("El Congreso", 31).

Es preciso, sin embargo, señalar que en el texto que, de acuerdo con la mayoría de los críticos, abre esta serie de acercamientos de Borges a la mística, presenta algunas particularidades. Nos referimos a "Sentirse en muerte", publicado por primera vez en El idioma de los argentinos (1928). ${ }^{20}$ Es un texto que se presenta como registro de una experiencia, e incluso Gamerro y Lefere entienden que en él se plasma un momento

${ }^{20}$ Como se sabe, Borges impidió que ese libro de ensayos se reeditara durante su vida y lo excluyó de sus obras completas. Sin embargo, "Sentirse en muerte" fue recogido, primero en Historia de la eternidad (1936) y luego en Nueva refutación del tiempo (1947), que sería posteriormente incluido en Otras inquisiciones (1952). Kodama lee en estas sucesivas reediciones un índice de la importancia que este texto tenía para su autor (“Jorge Luis Borges y la experiencia mística”, 83). 
de éxtasis o revelación que efectivamente vivió Borges, aunque niegan que deba considerarse de tipo místico. ${ }^{21}$ Con respecto a lo que aquí nos interesa, lo notable es que, en "Sentirse en muerte", la experiencia parece (más) posible de ser transmitida discursivamente, por medio de la escritura: "[...] me sospeché poseedor del sentido reticente o ausente de la inconcebible palabra eternidad. Sólo después alcance a definir esa imaginación. La escribo, ahora, asî" ("Sentirse en muerte”, 132, el destacado es mío). ${ }^{22}$ Entre esta primera aproximación, donde el éxtasis es definible, escribible y los textos posteriores, donde la experiencia es incomunicable, se sitúa "El acercamiento a Almotásim".

Recordemos que este texto apareció en la sección "Dos notas", del libro de ensayos Historia de la eternidad (1936). "Almotásim” se presenta como la reseña de "la primera novela policial escrita por un nativo de Bombay City". El propio escritor y la crítica han señalado el carácter fundacional de este relato para la literatura borgeana en tanto se constata allí el descubrimiento de un "formato", "una combinación de la ficción con el ensayo" (Rodríguez Monegal, Borges, 240) que será después uno de los rasgos más característicos de los textos reunidos en Ficciones y en El Aleph, que cimentarían el reconocimiento internacional de su autor. ${ }^{23}$ Entendemos que en la historia del joven indio que recorre su ciudad buscando al "hombre llamado Al-Mu'Tasim" puede leerse también una toma de posición respecto a la literatura "mística", que se sostendrá en los textos posteriores en los que Borges vuelva a entrar en diálogo con esta tradición..$^{24}$ Aparecido sólo algunos meses después de la reseña

\footnotetext{
${ }^{21}$ Borges abre "Sentirse en muerte" diciendo "Deseo registrar aquí una experiencia que tuve hace unas noches..." (129). Gamerro entiende que se trata de "la experiencia personal de Borges más cercana a las que aquí hemos estado tratando" ("Borges y la tradición mística", 107). Lefere por su parte sostiene "Con respecto a 'Sentirse en muerte', recordemos que no se refiere a una experiencia propiamente mística sino, con circunspección, a una exclusivamente subjetiva de éxtasis" (Borges..., 118).

${ }^{22}$ Gamerro entiende que esta experiencia permanece "dentro del terreno de lo comunicable" justamente porque no se trata de una experiencia mística ("Borges y la tradición mística", 108).

${ }^{23}$ En otro lugar (“¿No hay fuera del texto?”) hemos propuesto que este texto puede leerse, en los términos propuestos por Dominique Maingueneau (Discurso literario, 252) como un relato que apela a la "escenografía" de una reseña literaria.

${ }^{24}$ La relación de "Almotásim" con la mística es explicitada en el mismo texto. Se nos dice que, en la supuesta novela india, "los puntuales itinerarios del héroe son de algún
} 
de El buque, es posible interpretar "Almotásim" en continuidad con el problema que Borges se planteaba en su lectura del libro de Bernárdez, esto es, ¿cómo se da cuenta de una experiencia mística?

\section{Un consejo desoído}

En 1929, Borges publica su tercer poemario, Cuaderno San Martín. En esta primera edición, el libro se cierra con una serie de notas que fueron eliminadas en ediciones posteriores. En una de ellas, titulada "El ángel de la guarda en Avellaneda", encontramos un texto que puede considerarse como un hipotexto de "Almotásim" y que está, significativamente, destinado al futuro autor de El buque. ${ }^{25}$ Allí Borges presenta su posición respecto del modo en que debe realizarse literariamente la manifestación de lo sobrenatural:

Por Carlos Mastronardi, en noche de discusión y de caminata, supe que Francisco Luis Bernárdez, compartida amistad, pensaba dirigir un poema al Ángel de su Guarda. Conversamos de qué manera lo causalizaría y propuse estas cosas.

Descartada una aparición visible del Ángel, por inconvincente, sólo restaba su aparición en ternura. Esa visitación era obligatorio que fuera en lugar odioso o insípido, incapaz de producirla personalmente, y a hombre en soledad. Éste, caminando en horas desabridas del amanecer por un barrio de fábricas o realizando un trayecto habitual en ferrocarril o en largo tranvía, padece una tempestad de dulzura. Entiende que esa invasión no es desde las cosas ni desde persona lejana que lo está queriendo en ese momento (porque ninguna mujer le está dedicada) ni tampoco desde sí mismo, porque su alma sabe qué hospeda. Resuelve entonces que esa incomprensible dulzura viene del Ángel (Borges, Cuaderno San Martín, 96-97).

modo los progresos del alma en el ascenso místico" y que existen puntos de contacto entre esta obra y el Coloquio de los pájaros, del místico persa Attar (“Almotásim”, 417).

${ }^{25}$ Gerard Genette denomina hipertextualidad a "la relación que une un texto B (que llamaré hipertexto) a un texto anterior A (al que llamaré hipotexto) en que se injerta de una manera que no es la del comentario [...] Llamo, pues, hipertexto, a todo texto derivado de un texto anterior por transformación simple o por transformación indirecta (imitación)" (Palimpsestos, 15-17). 
La epifanía angélica, para Borges, debe ser indirecta, debe escamotearse al lector el espectáculo de lo sobrenatural. Bernárdez publicó un poemario titulado El ángel de la guarda recién en 1949, y no parecen haber quedado allí rastros de la propuesta borgeana. Ignorando los consejos de su amigo, el poeta efectuará en ese texto la "inconvincente" aparición visible del ángel:

[...] Advertí que la luz se condensaba.

Y que de su imprecisa nebulosa surgía, más radiante que una estrella, una figura extrañamente hermosa.

Con toda el alma sumergida en ella, contemplé la belleza más que humana que despuntaba de la luz aquella.

Y distinguí la forma sobrehumana de un Ángel que brillaba ante mi frente con una refulgencia soberana (Bernárdez, El ángel de la guarda, 18).

Sin embargo, un eco de aquella propuesta desoída puede leerse, retomada por el mismo Borges, en "Almotásim". En el argumento de la obra, tal como la presenta el reseñador, encontramos una notable similitud con la propuesta de "El ángel de la guarda en Avellaneda":

Un hombre, el estudiante incrédulo y fugitivo que conocemos, cae entre gente de la clase más vil y se acomoda a ellos, en una especie de certamen de infamia. De golpe - con el milagroso espanto de Robinson ante la huella de un pie humano en la arena- percibe alguna mitigación de infamia: una ternura, una exaltación, un silencio, en uno de los hombres aborrecibles. "Fue como si hubiera terciado en el diálogo un interlocutor más complejo." Sabe que el hombre vil que está conversando con él es incapaz de ese momentáneo decoro: de ahí postula que éste ha reflejado a un amigo, o amigo de un amigo. Repensando el problema, llega a una convicción misteriosa: "En algún punto de la tierra hay un hombre de quien procede esa claridad; en algún punto de la tierra está 
el hombre que es igual a esa claridad". El estudiante resuelve dedicar su vida a encontrarlo (Borges, “Almotásim”, 416, el destacado es mío).

"Almotásim" tendría entonces un posible origen en una nota de Borges que surge en diálogo con el proyecto de un poeta católico. Y entendemos que, más allá de esta vinculación genética, la cercanía entre sus fechas de publicación y las continuidades perceptibles entre la reseña de Borges sobre El buque y su propio relato nos permiten leer "Almotásim" en diálogo, o mejor, en contrapunto polémico con la obra de Bernárdez. En ambos textos tenemos una búsqueda - del misterioso origen de una música, del hombre que es origen de la "claridad" - con una evidente resonancia simbólica. Sin embargo, la resolución es, para cada caso, radicalmente distinta. En el poema, el yo lírico alcanza la revelación, la comunica a los lectores y finaliza con el alma sosegada. "Almotásim" en cambio, muestra todo el camino hacia la revelación, pero el relato no llega a dar cuenta de ella, se detiene exactamente en el umbral:

Al cabo de los años, el estudiante llega a una galería "en cuyo fondo hay una puerta y una estera barata con muchas cuentas y atrás un resplandor". El estudiante golpea las manos una y dos veces y pregunta por Almotásim. Una voz de hombre - la increíble voz de Almotásim - lo insta a pasar. El estudiante descorre la cortina y avanza. En ese punto la novela concluye (416).

Donde Bernárdez prodiga palabras que se pretenden reveladoras, Borges coloca el punto final. A propósito de este mismo fragmento de "Almotásim", afirma Gamerro: "La revelación mística siempre está del otro lado de esa puerta, de ese umbral donde terminan el lenguaje y la literatura. Un hombre puede pasar esa cortina, pero al hacerlo ha quedado fuera de nuestro alcance, se ha salido del relato. Aunque vuelva, lo que haya visto del otro lado, no puede contárnoslo" ("Borges y la tradición mística", 109). Años después en "La muralla y los libros" ( $L a$ Nación, 1950), el escritor definiría el hecho estético como "inminencia de una revelación, que no se produce" (13). Podemos pensar, entonces,

26 "El cielo se apodera / Para siempre del alma enamorada / Y una paz duradera / Y desinteresada / Va sucediendo a la inquietud pasada" (Bernárdez, El buque, 114). 
que el defecto de El buque radica en hacer explícito lo que debería permanecer como inminencia, alusión, en operar la aparición visible del ángel en lugar de limitarse a sugerirla.

\section{Modos de leer}

Otro de los puntos que Borges había objetado en su reseña del poema de Bernárdez, estrechamente vinculado a la finalidad didáctica que detectaba en el texto, era el modo de lectura que este proponía:

Muchos lectores [...] ignorarán qué clase de lectura se espera de ellos. "El buque" es un poema narrativo en primera persona que comprende un sólo lugar y una sola noche; esos lectores interrogarán si el poeta les propone el relato - metafórico o literal - de una sola y concreta experiencia mística, o si ha querido alegorizar un largo proceso. Yo creo que lo segundo es lo cierto, pero que debemos leer el poema según la primera interpretación. Debemos leerlo a modo de novela y no de adivinanza. Es el caso de todas las alegorías, y aún de la más famosa y mejor: "El progreso del peregrino, de este mundo a aquel otro que vendrá", del visionario puritano Juan Bunyan. Abandonarse al puro goce de la lectura: tal es el proceder que recomiendo, al menos al principio ("El buque", 133).

El escritor contrasta entonces dos acercamientos posibles al texto, el que podemos denominar novelístico, que pone el foco en la singularidad de la experiencia narrada, y el alegórico, que no se detiene en las particularidades de lo que se cuenta sino que busca atravesarlas para alcanzar un significado subyacente, oculto $-\mathrm{y}$ en este sentido, Borges habla de "adivinanza". En "Almotásim", estas formas diversas de leer se encarnan directamente en dos ediciones distintas de la supuesta novela india:

En la versión de 1932, las notas sobrenaturales ralean: "el hombre llamado Almotásim" tiene su algo de símbolo, pero no carece de rasgos idiosincrásicos, personales. Desgraciadamente esa buena conducta literaria no perduró. En la versión de 1934 - la que tengo a la vista - la novela decae en alegoría Almotásim es emblema de Dios y los puntuales itinerarios del héroe son de algún modo los progresos del alma en el ascenso místico (417).

En ambos casos, queda claro que la lectura - o la versión - alegó- 
rica es inferior a la lectura novelística. El escritor ya se había referido desdeñosamente a la alegoría en una nota sobre el Quijote publicada en la revista católica Criterio $^{27}$ y, en trabajos posteriores, la definirá directamente como un "error estético" ("De las alegorías a las novelas", 122). ${ }^{28}$ El problema de este modo de leer es, de nuevo, el afán de univocidad: cada personaje y cada situación apuntan a un único significado, que debe ser decodificado - adivinado - por el lector. La intuición de Borges en su reseña parece correcta: en El buque, según declarará posteriormente su autor, los distintos elementos del texto poseen un significado preciso, que proviene de la teología cristiana. Al recordar el proceso de composición del texto, en una conferencia de 1970, el poeta afirma que tenía definido el significado simbólico aún antes de haber escrito un sólo verso.

Pensé en un buque porque el buque tenía una connotación mística, cristiana. [...] De manera que tenía que ser una nave el símbolo más adecuado para representar el advenimiento de la gracia. De esa gracia la música podía ser lo esencial. Esto nos llevará muy lejos por el camino del simbolismo. Por ejemplo, el hecho de que la nave tiene tres mástiles tiene un sentido pitagórico y al mismo tiempo cristiano, recuerda todo lo que para nosotros significa el número tres: la Santísima Trinidad, las tres virtudes teologales [...] Pero he aquí que ocurre algo curioso e inesperado. Cuando yo tenía en mi mente ese buque, no contaba con ningún verso formado (apud Roffé, El buque, 22).

Borges entonces, identifica claramente la intención didáctica de Bernárdez. Pero sostiene que la interpretación que espera el autor conspira contra el "puro goce de la lectura" ("El buque", 133). Realiza entonces una operación crítica análoga a la que propondrá para otros escritores católicos: valora la producción de Bernárdez leyéndola “a contrapelo"de

27 “Ni lo paródico ni lo alegórico son valederas manifestaciones de arte. [Lo alegórico] es una categoría gramatical más que literaria, una seudo humanización de voces abstractas por medio de mayúsculas" (Borges, "La conducta novelística de Cervantes", 55).

${ }^{28}$ No podemos detenernos aquí en un problema que, no obstante, queremos dejar consignado. La alegoría, un tema recurrentemente discutido en los ensayos de Borges, se presenta bajo una doble faz que no se define con claridad. Por momentos se entiende como un género, un corpus determinado de obras, mayoritariamente medievales. Por momentos se entiende como un modo de leer que puede ser ejercido sobre determinados textos (v.g., el Quijote o la Divina Comedia) que admiten también una lectura literal. 
lo que el propio escritor quiso sugerir. ${ }^{29}$ No le interesará el "largo proceso" alegorizado sino el relato de una experiencia concreta.

En la reseña de $E l$ buque puede identificarse ya una estrategia que Borges aplicará también a otras obras del ámbito cristiano - Chesterton, Bloy - e incluso a la Biblia: una lectura literal, que ignora o pone en suspenso los significados morales y teológicos, para concentrarse en el valor estético del texto, que no busca interpretar sus significados profundos sino describir su superficie. ${ }^{30}$ Ciertas obras firmadas por escritores católicos, como Bernárdez, pueden ser literariamente válidas, siempre que no se las lea como "literatura católica", es decir, buscando en ellas la enseñanza moral o el sentido trascendente. De este modo, Borges reconoce el valor singular de El buque, negando algunos elementos fundamentales de la estética que su autor sostiene. ${ }^{31}$

\section{A modo de conclusión}

Para finalizar, podemos incluso ir más allá y afirmar que la lectura borgeana discute - oblicuamente - con los presupuestos teológicos de Bernárdez y los poetas del Convivio. Al hablar de la naturaleza "escolar" de la revelación en El buque, Borges parece estar deslizando una crítica directa a la teología neoescolástica que se enseñaba en los CCC y

${ }^{29}$ Esta operación es muy patente en la lectura que Borges propone de Gilbert K. Chesterton, un escritor que era muy admirado por los intelectuales católicos de los CCC y el Convivio. El mismo año en que se publica la reseña de "El buque" y "Almotásim", Borges escribe la nota necrológica del escritor inglés para Sur. Allí celebra los relatos policiales del Padre Brown, pero renegando de su componente didáctico: "Chesterton [...] fue un incomparable inventor de cuentos fantásticos. Desgraciadamente, procuraba educirles una moral y rebajarlos de ese modo a meras parábolas" ("Modos de Chesterton", 20).

${ }^{30}$ Tomamos la noción de una lectura "literal" en un sentido similar al que propone Deleuze en su trabajo sobre "Bartleby, el escribiente" de Melville: "Bartleby no es una metáfora del escritor, ni el símbolo de nada. Se trata de un texto de una violenta comicidad, y lo cómico siempre es literal. [...]. No quiere decir más de lo que literalmente dice" (Deleuze, "Bartleby o la fórmula", 57). La oposición entre una hermenéutica de los significados profundos y una "erótica" de las superficies textuales se encuentra en "Contra la interpretación" (Susan Sontag).

${ }^{31}$ La estrategia de valorar la producción particular de algunos poetas católicos pero negando que estos representen una estética "grupal" válida aparece claramente en el prólogo de Borges a la Antología poética argentina (1941), al que ya hemos hecho alusión. 
que estaba en la base de la mayoría de los proyectos culturales y sociopolíticos de los intelectuales católicos. José Carlos Barcellos (“A terceira margem da ficção" 13-14) ha señalado, a propósito de los relatos de Ficciones, que en la literatura borgeana puede leerse una advertencia contra las teologías "racionalistas" (como la escolástica) que operan siempre a partir de la univocidad, que pretenden poseer respuestas acabadas y sistemáticas a los grandes misterios filosóficos y religiosos.

La reseña del libro de Bernárdez, especialmente si la leemos en continuidad con "Almotásim” parece poner en cuestión la posibilidad de un discurso racional (aunque esté "versificado") para hablar de Dios. ${ }^{32}$ Antes que dar respuestas "escolares" es preferible, como en "Almotásim”, no decir nada de lo que hay del otro lado de la puerta. Ya se sabe: de lo que no se puede hablar, mejor es callar.

\section{REFERENCIAS}

Adur, Lucas, “¿No hay fuera del texto? Un aporte al problema de la articulación texto-contexto desde el análisis del discurso". Ponencia presentada en el IV Congreso Internacional de Letras. Transformaciones culturales, Buenos Aires, 2010.

ADUR, Lucas, "El arte al servicio del renacimiento espiritual de nuestro pueblo. Jacques Maritain y los fundamentos de la estética católica argentina" en Actas de las II Jornadas Religar-Sur. Religión y sociedad en la Argentina contemporánea y países del Cono sur, C. Touris (coord.), Buenos Aires, Religar, 2011 (Cd-rom).

Adur, Lucas, "Simpatías y diferencias. Borges y la intelectualidad católica argentina en la segunda mitad de la década del veinte", Sociedad y religión, $38,2012,14-45$.

Adur, Lucas, "Hombres ya fulminados por Juvenal. Borges, crítico del mito de la nación católica" en Imaginario y nación: episodios, discursos, conceptos, Graciana Vázquez Villanueva, Marcelo Burello y Nicolás Bermúdez (comp.), Buenos Aires, Facultad de Filosofía y Letras, 2012, 109-144.

ARAgón, Roque Raúl, La poesía religiosa argentina, Buenos Aires, Ediciones Culturales Argentinas, 1967.

${ }^{32}$ En un sentido similar en "Historia de la eternidad" (1936), el ensayo que abre el volumen homónimo donde está contenido "El acercamiento a Almotásim”, leemos: "la sospecha de que las categorías de Dios pueden no ser precisamente las del latín, no cabe en la escolástica" (Borges, 360). 
BARCELlos, José Carlos, "A terceira margem da ficção: literatura e teologia em Jorge Luis Borges", Actas del I Coloquio Latinoamericano de Literatura y Teología, Cecilia Avenatti (coord.), Buenos Aires, Alalite (Cd-rom).

BERNÁRdEZ, Francisco Luis, El ángel de la guarda, Buenos Aires, Losada, 1949. Bernárdez, Francisco Luis, El buque [1935], Buenos Aires, Losada, 1998. Borges, Jorge Luis, "La conducta novelística de Cervantes", Criterio, 2, 1928, 55-56.

Borges, Jorge Luis, "Elementos de preceptiva" [1933], Borges en Sur, Buenos Aires, Emecé, 1999, 121-125.

Borges, Jorge Luis, "Modos de G. K. Chesterton" [1936] en Borges en Sur, Buenos Aires, Emecé, 1999, 18-23.

Borges, Jorge Luis, "Francisco Luis Bernárdez. El buque" [1936] en Textos recobrados 1931-1935, Buenos Aires, Emecé, 2001, 133-135.

BorgES, Jorge Luis, "Historia de la eternidad" [1936] en Obras completas, I, Buenos Aires, Emecé, 2002, 353-367.

Borges, Jorges Luis, "El acercamiento a Almotásim" [1936] en Obras completas, I, Buenos Aires, Emecé, 2002, 414-418.

BorgEs, Jorge Luis, "El Aleph" [1945] en Obras completas, I, Buenos Aires, Emecé, 2002, 617-627.

Borges, Jorge Luis, "La escritura del Dios" [1949] en Obras completas, I, Buenos Aires, Emecé, 2002, 596-599.

BorgEs, Jorge Luis, "De las alegorías a las novelas" [1949] en Obras completas, II, Buenos Aires, Emecé, 2004, 122-124.

Borges, Jorge Luis, "Mateo xxv, 30" [1953] en Obras completas, II, Buenos Aires, Emecé, 2004, 252.

BorgES, Jorge Luis, "El congreso" [1971] en Obras completas, III, Buenos Aires, Emecé, 2004, 20-32.

Borges, Jorge Luis, Adolfo Bioy Casares y Silvina Ocampo, Antología poética argentina, Buenos Aires, Sudamericana, 1941.

Bourdieu, Pierre, Las reglas del arte. Génesis y estructura del campo literario [1992], trad. Thomas Kauf, Barcelona, Anagrama, 1995.

Charaudeau, Patrick y Dominique Mainguenau (dir.), Diccionario de análisis del discurso [2002], trad. Irene Agoff, Buenos Aires, Amorrortu, 2005.

Соваs Carral, Andrea, "Modos de refundarse. Los casos de Borges, Bioy y Silvina Ocampo", en La década infame y los escritores suicidas (1930-1943), María Pía López (comp.), Buenos Aires, Paradiso, 2007, 83-95.

Deleuze. Gilles "Bartleby o la fórmula" en Preferiría no hacerlo, Gilles Deleuze, Giorgio Agamben y José Luis Pardo, Valencia, Pre-textos, 2009, 57-92.

Dell'oro Maini, Atilio, “Las características del Convivio", Criterio, 53, 1929, 297-298. 
Di StÉFAno, Roberto y Zanatta, Loris, Historia de la Iglesia argentina, Buenos Aires, Mondadori, 2000.

Gamerro, Carlos, "Borges y la tradición mística” en El nacimiento de la literatura argentina y otros ensayos, Buenos Aires, Norma, 2006, 93-111.

García, Carlos, El joven Borges, poeta, Buenos Aires, Corregidor, 2000.

Genette, Gerard, Palimpsestos. La literatura en segundo grado [1962], trad. Celia Fernández Prieto, Madrid, Aguilar, 1989.

Genette, Gerard, Umbrales [1987], trad. Susana Lage, Buenos Aires, Siglo XXI, 2001.

JAMES, William, Las variedades de la experiencia religiosa [1902], trad. J.F. Yvars, Buenos Aires, Hyspamérica, 1986.

JuAn de la Cruz, "Noche oscura" y "Cántico espiritual” y "Comentario en prosa al poema cántico espiritual" en Poesía completa y comentarios en prosa, Buenos Aires, Planeta, 2003, 3-10 y 154-336.

KodAma, María, "Jorge Luis Borges y la experiencia mística" en El sol a medianoche. La experiencia mística: tradición y actualidad, Luce López Baralt y Lorenzo Piera (ed.), Madrid, Trotta, 1996, 77-84.

LEFERE, Robin, Borges entre autorretrato y automitografía, Madrid, Gredos, 2005.

LóPEz-Baralt, Luce, "La experiencia mística: tradición y actualidad" en El sol a medianoche. La experiencia mística: tradición y actualidad, Luce López Baralt y Lorenzo Piera (ed.), Madrid, Trotta, 1996, 9-22.

López-Baralt, Luce, "Los paseos de Borges por Constitución: la clave secreta de un emblema místico privado" en El siglo de Borges, I, Alfonso de Toro y Fernando de Toro (ed.), Madrid, Iberoamericana, 1999, 151-169.

López-Baralt, Luce y Emilio Báez, “¿Vivió Jorge Luis Borges la experiencia mística del Aleph?" en El sol a medianoche. La experiencia mística: tradición y actualidad, Luce López Baralt y Lorenzo Piera (ed.), Madrid, Trotta, 1996, 251-264.

Lvovich, Daniel, Nacionalismo y antisemitismo en la Argentina, Buenos Aires, Ediciones B, 2003.

MARTínez Cuitiño, Luis (dir.), La vanguardia católica argentina y el grupo de Convivio, Buenos Aires, mimeo, 1997-1998.

Maturo, Graciela, "Francisco Luis Bernárdez, poeta de la noche y el alba" en Antología, Francisco Luis Bernárdez, Buenos Aires, Secretaría de Cultura de la Nación / Bonum, 1994, 11-26.

MÉnDEZ, Evar, "Rol de Martín Fierro en la renovación poética actual" en Exposición de la actual poesía argentina (1922-1927), Pedro Juan Vignale y César Tiempo (selección), Minerva, Buenos Aires, 1927, XII-XVIII.

Montaldo, Graciela, "Consagraciones: tonos y polémicas” en Yrigoyen entre 
Borges y Arlt, Graciela Montaldo (comp.), Buenos Aires, Paradiso, 2006, $30-42$.

Palazuelos Montesinos, Juan Carlos, "Jesús en la literatura de Jorge Luis Borges”, Intus-Legere, 4, 2001, 231-240.

Rodríguez Monegal, Emir, Borges, Una biografía literaria [1978], trad. Homero Alsina Thevenet, México, Fondo de Cultura Económica, 1993.

Roffé, Mercedes, "Prólogo" y "Notas" en El buque, Francisco Luis Bernárdez, Buenos Aires, Losada, 1998.

Scholem, Gershom, Las grandes tendencias de la mística judía [1941], trad. Beatriz Obërlander, Buenos Aires, Fondo de Cultura Económica, 1993.

SonTAG, Susan, "Contra la interpretación" [1964], en Contra la interpretación, Buenos Aires, Alfaguara, 2005, 25-39

Vignale, Pedro Juan y Tiempo, César (coord.), Exposición de la actual poesía argentina (1922-1927), Minerva, Buenos Aires, 1927. 